\title{
Parathyroid carcinoma: case report
}

\author{
G. STURNIOLO ${ }^{1}$, E. GAGLIANO²* A. TONANTE², F. TARANTO², E. PAPALIA², \\ R. CASCIO ${ }^{2}$, C. DAMIANO ${ }^{2}$, F. VERMIGLIO ${ }^{1}$, G. STURNIOLO ${ }^{2}$
}

SUMMARY: Parathyroid carcinoma: case report.

G. Sturniolo, E. Gagliano, A. Tonante, F. Taranto, E. Papalia, R. Cascio, C. Damiano, F. Vermiglio, G. Sturniolo
The authors present a case of parathyroid carcinoma in a patient with primary hyperparathyroidism. Following a literature review, the clinical and diagnostic profile, treatment and prognosis of this rare disease are discussed.

KEY WorDS: Cancer - Hypercalcaemia - Hyperparathyroidism - Parathyroidectomy - Recurrence.

\section{Introduction}

Parathyroid carcinoma is a rare cancer. The first known case, described by De Quervain in 1909, was a non-functional tumor whose malignancy was only revealed by the lesion's macroscopic features. In 1929 Wilder described a case in a patient with primary hyperparathyroidism admitted to the Mayo Clinic. In 1938 Armstrong reported another case of metastatic parathyroid carcinoma associated with primary hyperparathyroidism.

This cancer is responsible for $0.4-5.2 \%$ of cases of primary hyperparathyroidism. The $45-55$ year age group is the most affected, with a slight predominance of cases in women (1).

A case that came to our attention - the first in over 2500 total thyroidectomies and 40 parathyroid operations - prompted this paper and literature review to establish the current indications for the diagnosis and treatment of this rare disease.

\footnotetext{
"G. Martino" University Hospital, University of Messina, Messina, Italy ${ }^{1}$ Department of Clinical and Investigational Medicine and Pharmacology Endocrinology Unit

2Department of General and Specialist Surgery

Gastrointestinal Surgery Unit

(Director: Giovanni Sturniolo)

*Corresponding Author: E. Gagliano, egagliano@unime.it

(c) Copyright 2013, CIC Edizioni Internazionali, Roma
}

\section{Case report}

The patient was a 35-year-old man with a family history of cancer. He was diagnosed with schizophrenia in 1990 and was under treatment with neuroleptic drugs. He had suffered from chronic kidney failure for around 10 years, under treatment with permanent dialysis. In February 2005, due to abnormal parathyroid values [parathyroid hormone, serum PTH: 1909 pg/mL (n.v. 12.0-72.0); and blood calcium: $11.4 \mathrm{mg} / \mathrm{dL}$ ] he underwent parathyroid scintigraphy with Technetium ${ }^{99 \mathrm{~m}}\left({ }^{99 \mathrm{~m}} \mathrm{Tc}\right)$-sestaMIBI-99/pertechnetate. This revealed a persistent delayed-phase hotspot in the lower part of the left thyroid lobe.

In March 2005, ${ }^{99 \mathrm{~m}} \mathrm{Tc}$ thyroid scintigraphy revealed a slightly enlarged thyroid gland with normal morphology and uneven intraparenchymal ${ }^{99 \mathrm{~m}} \mathrm{Tc}$ distribution and a circumscribed hotspot in the lower pole of the left lobe. Another hyper-functional nodular parathyroid growth was found in the lower right area.

A subsequent chest CT revealed moderate bilateral pleural effusion with imbibition and bilateral thickening of the oblique fissures. In the mediastinal area, there were multiple lymphadenopathies (maximum diameter $1.5 \mathrm{~cm}$ ) in the aortopulmonary window, Barety space and in the subcarinal area. There was also modest pericardial effusion and cardiomegaly, with multiple coronary calcifications and marked pulmonary artery ectasia. A chest X-ray revealed hypotrophy of the cervical vertebrae.

As the hyperparathyroidism worsened, the patient was admitted to our Surgery Unit, where he underwent surgical removal of lower left parathyroid growth $(>3 \mathrm{~cm})$ and left thyroid lobe with central lymphectomy. Histological examination of the surgical specimen confirmed the diagnosis of parathyroid carcinoma with clear cell and oncocytic features (Figs. 1, 2).

Post-operative blood calcium levels remained elevated (14.5 $\mathrm{mg} / \mathrm{dL}$; n.v. 8.2-10.4), while serum parathyroid hormone levels 6 days post-surgery $(1850 \mathrm{pg} / \mathrm{mL}$; n.v. 12.0-72.0) were even higher than the preoperative value $(1408 \mathrm{pg} / \mathrm{mL})$.

A suspected distant metastasis led to total body scintigraphy ${ }^{99 \mathrm{~m}} \mathrm{Tc}$-sestaMIBI), which revealed two hotspots: the first on the ri- 


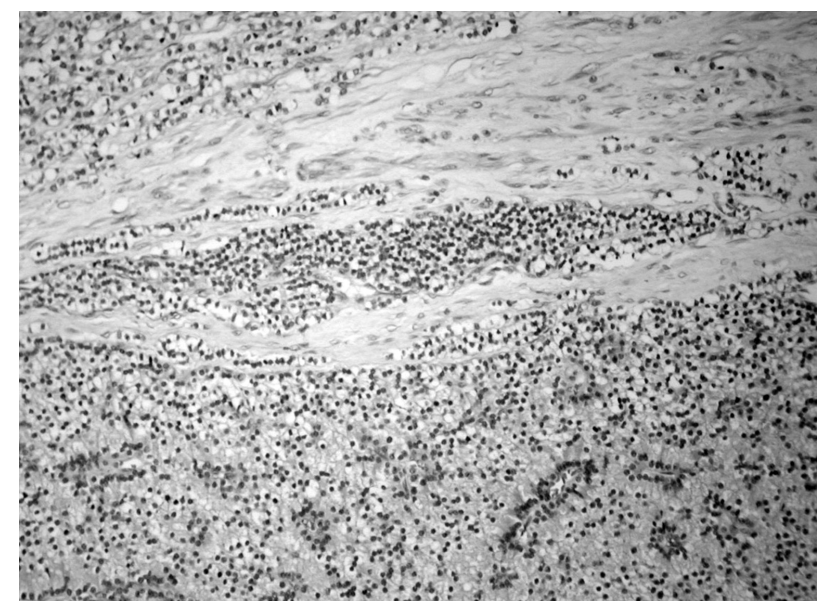

Fig. 1 - Well differentiated parathyroid adenocarcinoma. Stromal infiltration. (H\&E, original magnification 200x).

ght, between the lower pole of the thyroid lobe and the underlying sternoclavicular joint, and the second in the midline, just above the jugulum, corresponding to the site of the primary tumor. There were also three hotspots in the left apical area of the lung. The tumor had thus metastasized both locally and distally just three months after surgery, demonstrating its high degree of malignancy.

Chemoimmunotherapy was begun after referral to an oncologist, but the patient died two months later.

\section{Discussion}

The main signs and symptoms of parathyroid carcinoma are due to high calcium and PTH levels. They include pathological fractures, joint and bone pain, fatigue, polyuria and polydipsia, kidney stones, muscular asthenia, nausea, vomiting, loss of appetite and weight loss.

These signs and symptoms are typical of primary hyperparathyroidism and also arise in patients who do not have a parathyroid carcinoma. They should therefore not be considered cancer-specific.

Diagnosis is more problematic in non-functional lesions, and the prognosis is worse. A visible or palpable lump in the front of the neck or ultrasound or CT evidence may give rise to the suspicion of parathyroid carcinoma. Where the lesion can be palpated, it appears as a hard, solid mass of from a few millimeters to some centimeters in size, strongly adherent to the thyroid and infiltrating the adjacent structures.

High serum calcium $(>14 \mathrm{mg} / \mathrm{dL}$ ) and PTH (especially when twice the normal value) are considered as indicative of carcinoma.

\section{Diagnosis}

In most cases, the suspected diagnosis of parathyroid carcinoma was reached on the basis of clinical signs and

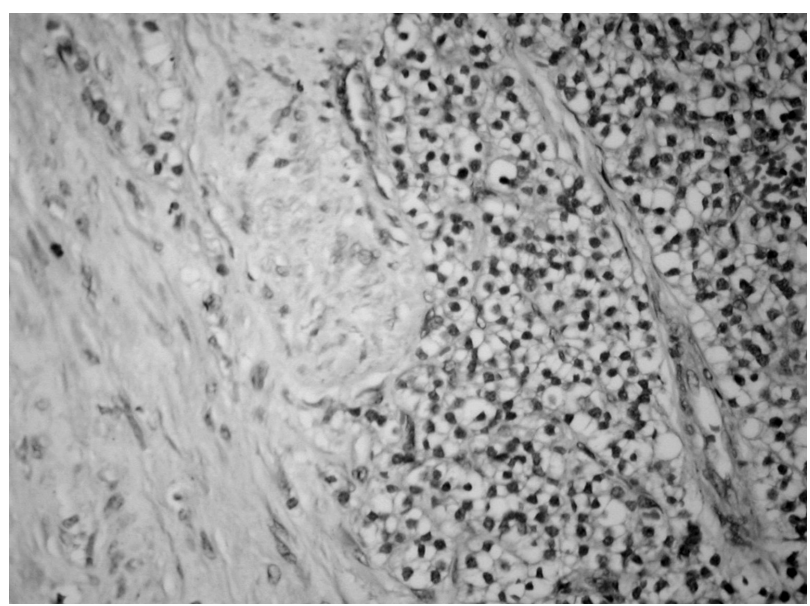

Fig. 2 - Isometric view of the infiltration, revealing cells with regular nuclei and clear vacuolated cytoplasm (H\&E, original magnification 400x).

the finding of hypercalcemia, hypophosphatemia and elevated alkaline phosphatase and osteocalcin, markers of increased osteoclast activity. As already noted, the diagnosis is almost certain when there are particularly high PTH and calcium levels, which are unlikely to be seen in cases of benign hyperparathyroidism.

Although instrumental diagnosis is non-specific, ultrasound can reveal some signs of malignancy, such as echostructure, irregular margins, any pathological adenopathies and any invasion of the adjacent structures. Computed tomography (CT), magnetic resonance imaging (MRI), bone scintigraphy with ${ }^{99 \mathrm{~m}} \mathrm{Tc}$-sestaMIBI and bone scintigraphy and fine-needle aspiration biopsy (FNAB) can help confirm the diagnosis. However, the definitive diagnosis is provided by the pathologist.

On macroscopic examination, the tumor is hard; whitish with a very thick fibrous capsule. It is strongly adherent to the surrounding tissues. Capsule invasion is considered a sign of malignancy. Under the microscope, capsule, blood vessel and lymph invasion, stromal calcifications, fibrous trabeculae, enlarged nuclei and strong mitotic activity are considered to be signs of malignancy.

\section{Treatment}

Surgery is the gold standard for the treatment of parathyroid carcinoma. En bloc dissection of the tumor with the thyroid lobe, the ipsilateral parathyroid and any other affected tissue is the most suitable treatment and leads to the best prognosis. The radicalism of the surgery is important and it is essential to avoid damaging the tumor capsule, as any residual or dispersed cells could lead to a fast recurrence.

Sometimes it is possible to remove local recurrences. Laterocervical and central lymphadenectomy is generally carried out only if necessary. 
Some authors consider radiotherapy to have some effect on preventing recurrences when used as a complementary treatment, while chemotherapy is agreed by all to be ineffective.

The treatment of parathyroid carcinoma aims not only to cure the disease but to obtain its biochemical remission: normalization of blood calcium and PTH levels, arrest of bone calcium depletion and regression of vascular, renal and neurological disorders. Continued high postoperative calcium and PTH levels are a sign of the disease's persistence (metastasis or residual disease). Followup involves periodic monitoring of calcium and PTH levels, markers for the disease's recurrence.

The outcome of surgery depends on a series of factors which together determine the prognosis. The most important factor is early diagnosis. However, the extreme variability of the biological behavior of each individual tumor should be borne in mind. Some relapse soon after surgery, especially locally, while others can remain dormant for several years before giving rise to distal metastasis. The presence and size of any locoregional metastasis at the time of surgery do not seem to influence the prognosis. Long-term survival is reported as $40-86 \%$ at 5 years and around $49 \%$ at 10 years. In the event of recurrence, survival at 5 years is $0 \%(9-13)$.

\section{References}

1. Favia G. et al. Il carcinoma delle paratiroidi. In: La patologia chirurgica della tiroide e delle paratiroidi. Pagg. 266-2, Club delle UEC 2000 (www.clubdelleuec.it).

2. Wassif WS, Minitz CF, Friedman E, et al. Familial isolated hyperparathyroidism: a distinct genetic entity with an increased risk of parathyroid cancer. J Clin Endocrinol Metabol 1993;77(6):148589.

3. Maher W Khan BS, Elaine M Worcester MD, Francis H Straus II MD, Shaher Khan M, Staszak BS, MS, Edwin L Kplan MD FACS. Parathyroid carcinoma in secondary and tertiary hyperparathyroidism. J Am Coll Surg 2004;199:312-319.

4. Vetto JT, Brennan MF, Woodruf J, et al. Parathyroid carcinoma: diagnosis and clinical history. Surgery 1993;114(5):882-892.

5. Fujimoto Y, Obara T. How to recognize and treat parathyroid carcinoma. Surg Clin North America 1987;67:343-357.

6. Levin K, Galante M, Clark O: Parathyroid carcinoma versus parathyroid adenoma in patients with profound hypercalcemia. Surgery 1987;101:647-660.

7. Shane E. Parathyroid carcinoma. J Clin Endocrinol Metabol 2001;86:485-493.

8. Hansen CP, Pedersen ML, Christensen L. Diagnosis, treatment and outcome of parathyroid cancer: a case report of eight patients. Eur J Sur 1991;157:517-520.

9. Pelizzo MR, Piotto A, Bergamasco A, Rubello D, Casara D. Il carcinoma delle paratiroidi (Strategie terapeutiche derivate da 20 anni di esperienza) Min Endocrinol 2001;26(1):23-30.

10. Mittendorf EA, McHenry CR. Parathyroid carcinoma. J Surg On-

\section{Conclusions}

Our case of parathyroid carcinoma was typical of most cases reported in the literature. The literature review revealed that this type of cancer is rare, and usually occurs in people in their 40s. Many cases are sporadic, although familial hyperparathyroidism is a rare, autosomal dominant condition that is associated with an increased risk of cancer $(2,14)$.

Approximately 1-2\% of cases of hyperparathyroidism are caused by parathyroid carcinoma. It is most commonly found in patients with primary hyperparathyroidism, but is less common in secondary or tertiary forms $(4,15)$. Functional carcinomas produce parathyroid hormone, which causes hypercalcemia and signs of bone or kidney disease $(3,18)$.

The real incidence of parathyroid carcinoma is difficult to establish, due to variable diagnostic criteria $(5,16)$. Its histological features are not specific, as they have also been found in adenomas or even local recurrences of benign tumors $(6,17)$. For this reason, the tumor's malignancy must be unequivocally confirmed only after prolonged follow-up, bearing in mind both histological (capsular and vascular invasion) and clinical features (invasive appearance, recurrences, distal metastasis) $(7,8,19,20)$.

col 2005;89(3):136-42.

11. Fang SH, Lal G. Parathyroid cancer. Endocr. Pract. 17 supl 1 : 36432011

12. Shattuck TM, Valimaki S, Obara T, et al. Somatic and germ-line mutations of the HRPT2 gene in sporadic parathyroid carcinoma. N Engl J Med 2003;349:1722-29.

13. Wynne AG, van Heerden J, Carney JA, et al. Parathyroid carcinioma: clinical and pathological features in 43 patients. Medicine (Baltimore) 1992;71:197-205.

14. Obara T, Fujimoto Y. Diagnosis and treatment of patients with parathyroid carcinoma: An update and review. World J Surg 1993;17:820-29.

15. Grammes CF, Eyerly RC. Iperparathyroidism and parathyroid carcinoma. South Med J 1980;73:814-16.

16. Munson ND, Foote RL, Northcutt RC, et al. Parathyroid carcinoma: is there a role for adjuvant radiation therapy? Cancer 2003;98:2378-84.

17. Sandelin K, Auer G, Bondeson L, Grimelius L, Farnebo LO. Prognostic factors in parathyroid cancer: A review of 95 cases. World J Surg 1992;16:724-31.

18. Marcocci C, Cetani F, Rubin MR, Silverberg SJ, Pinchera A, Bilezikian JP. Parathyroid carcinoma. J Bone Miner Res 2008;23:186980 .

19. Schantz A, Castelman B. Parathyroid carcinoma. A study of 70 cases. Cancer 1973;31:600-605.

20. Owen RP, Silver CE, Pellitteri PK, et al. Parathyroid carcinoma. A review. Head Neck 2011;33(3):429-36. 